SHS Web of Conferences 2, 00043 (2012)

DOI: $10.1051 /$ shsconf $/ 20120200043$

(C) Owned by the authors, published by EDP Sciences, 2012

\title{
Developing disability management in the workplace
}

\author{
M. Zivitere and V. Claidze \\ Information Systems Management Institute, Latvia
}

\begin{abstract}
The authors of the article are concerned with how developing disability management in the workplace could open the possibilities for work for people with disability and can be matched with the opportunities of increasing the employment rate according to the European Disability Strategy (20102020) objectives as well as fighting against social exclusion and practical implementation of the United Convention on the rights of this group of people. As the statistical facts and figures show, there is a problem of inadequate employment among people with disabilities and there is a negative tendency in it. The topic of this article is related to the specific situation of disability management in the workplaces in Latvia, where there is an influence of the heritage from the past - the Soviet system, economic, legal and social issues. Interviewing experts and conducting extensive literature reviews within this context show that a considerable number of disability management problems have been possible solved in the enterprises of Latvia. On the basis of these essential findings, the areas of improvement have been identified following the European Disability Strategy. The abstract is elaborated within the framework of the Lifelong Learning Programme Leonardo da Vinci project "Ability not Disability in Employment" and financial support of the European Community.
\end{abstract}

Key words: ability to work, disability management, Latvia, workplace

Disability management is a different definition. The wide approach refers disability management as managing health-related absences from work and the risks that cause these absences in order to shorten or prevent them, improve workforce productivity, and reduce costs, which to be composed of three main components, as illustrated in Figure 1. (Treasury Board of Canada Secretariat. OCHRO Human resources management. http://www.tbs-sct.gc.ca/hrh/wds-mst/ disability-incapacite04-eng. asp).

Disability management system rapidly continues to evolve on the basis of social model thinking which is essentially different in comparison with the medical model of thinking (Bučiūniené, Kazlauskaité, 2010). The social model of thinking has important implications for all inclusion systems, and particularly for employment (Coskun, Živitere, Alexandrova, Firat, 2009). Disability management at the workplace has been given rather limited research attention (Roulstone, Gradwell, Price, Child, 2003), as well as summarizing of good practice (International Labour Office, 2010). This paper analyses developing disability management in the workplace only people with disabilities.

People with disabilities are a largely untapped employment resource in many countries: compared to their non-disabled peers, they are often underemployed or unemployed. As it is stated in the European Disability Strategy 2010-2020: A Renewed Commitment to a Barrier-Free Europe, "One in six people in the European Union (EU) has a disability that ranges from mild to severe making around 80 million who are often prevented from taking part fully in society and the economy because of environmental and attitudinal barriers... Furthermore, these numbers are set to rise as the EU's population ages" (European Disability Strategy 2010-2020). In 2007, Euro statistics concluded that the EU-wide employment rate (an individual is employed if having spent more than 7 months in employment (full-time and part-time work) during the income reference period) of the disabled is approximately 20 percentage points lower than the rate of the non-disabled (IZA Research Report 29,

This is an Open Access article distributed under the terms of the Creative Commons Attribution License 2.0, which permits unrestricted use, distribution, and reproduction in any medium, provided the original work is properly cited. 


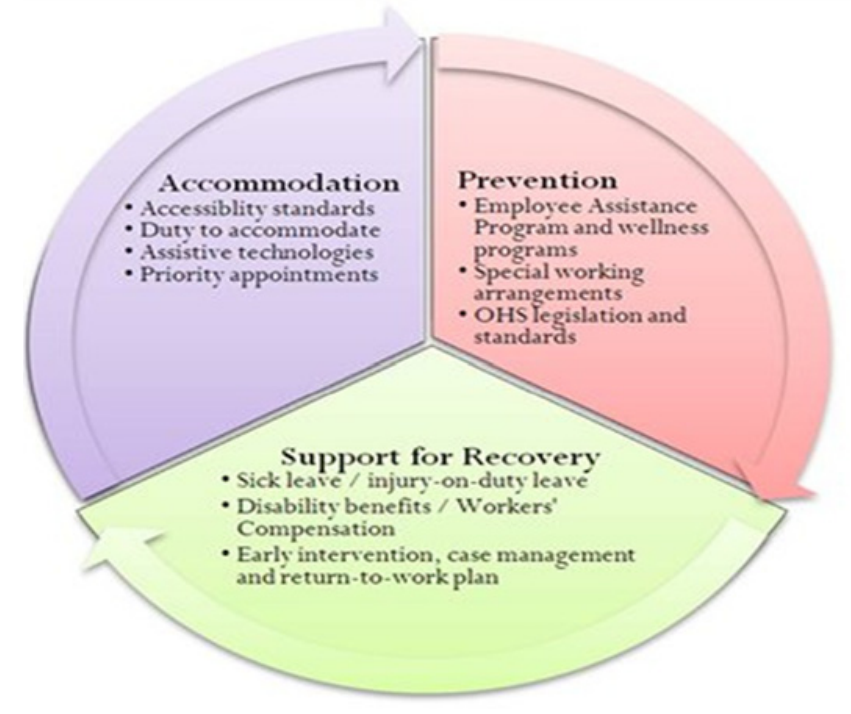

Figure 1. Three Main Components of a Workplace Disability Management System.

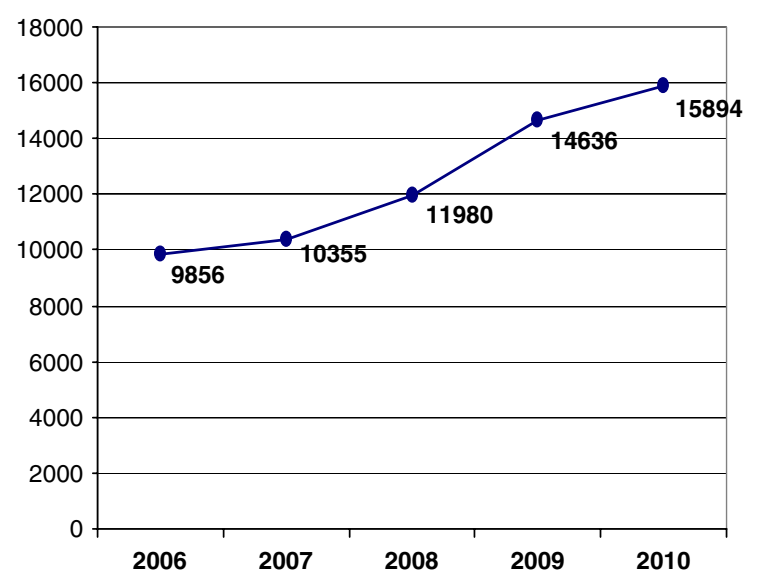

Figure 2. The number of new registered disabled people in Latvia.

2010). However, the rate of employment for people with disabilities is only around 50\% (European Disability Strategy 2010-2020).

As stated by several researches there are no common statistical data on the employment of people with disabilities in Latvia. Different state institutions have their own data base about people with disabilities or other matters in connection with disability. The Central Statistical Bureau of Latvia on the number of people with disabilities stated about $5 \%$ of population (Persons with disability in Latvia, 2007). State Social Insurance Agency performing the public administration functions in the area of social insurance and social services maintains a data base on general data of people with disabilities registered as employed persons or job seekers (see Figure 2). Figure 2 (http://www . docstoc.com/docs/70397149/) shows that the number of registered unemployed disabled people from 2000 till 2009 increased by three and a half times. Only 13-14\% of disabled people are employed (ANED Facts and figures, 2010). 
Int. Conf. SOCIETY. HEALTH. WELFARE; Congr. of Rehabilitation Doctors of Latvia

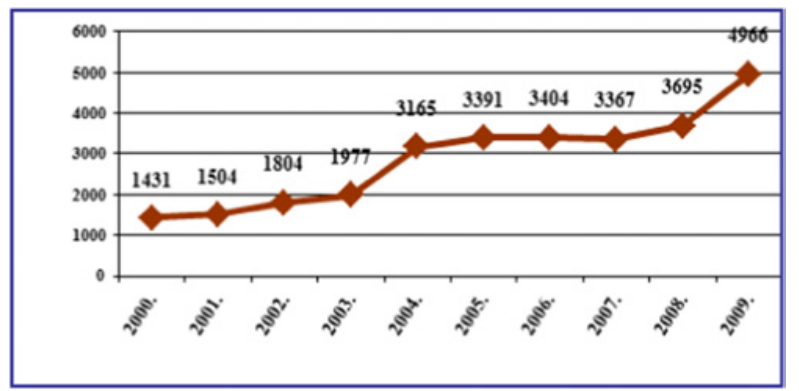

Figure 3. The registered number of unemployed disabled people (on February 28, 2009).

Figure 3 (Ibid.) shows that the number of new registered disabled people in Latvia from 2006 till 2009 increased by more than one and a half times. This tendency is extremely negative and it is a long-term tendency, which is not only connected to the current economic crises.

Consequently, figures one and two speak for themselves, which a situation of employing persons with disability does not correspond to the above mentioned Disability Strategy, objectives of reducing unemployment and fighting against social exclusion and practical implementation of the United Convention on the rights of this people group. The problems are inadequate employment persons with disabilities (Živitere, 2007).

Within this context, the authors view how developing disability management in the workplace could improve the ability of disabled persons to work, and can be matched with opportunities of increasing the employment in the current context, the authors examine the employers who had a possibility to develop disability management in the workplace.

\section{Materials and methods}

Disabled management in the workplace in Latvia is "related to the specific situation in the labour market of Latvia" (Ilena, 2007), under the influence of a heritage from the past - the Soviet system, where sheltered employment was practiced for people having disabilities (Bučiūniené, Kazlauskaité, 2010). Partially it is different when compared with the Old Europe. Despite long-standing commitments to achieve accessibility, concrete improvements have not been made at workplace levels in Latvia. Regulations and standards, if wherever they exist at all, are not implemented and enforced properly in all cases. Therefore there is no present common practice of disability management in the workplace. Nevertheless there are a few companies, which present a comprehensive and up-to-date overview of practices (management system, procedures, programmes, standards, guidelines etc.) and such studies should be promoted. The contemporary situation in the field of disabled management in Latvia in accordance with the criteria of positive practice in the EU countries has been investigated within the framework of the Leonardo da Vinci Pilot project Ability not Disability in Employment (AnDiW, 20092011) by the team of Information Systems Management Institute (Riga, Latvia). The human resources managers and senior managers of three different Latvian enterprises contributed to interviews regarding disabled management and initiated discussions on the way this management can be developed in the workplace.

There are the identifications of survey/interviews examining how employers manage working disabled people in the workplace, and how they survive or succeed at work.

Q1. Are there alternative recruitment qualifying tests and shift mechanisms to create a fair opportunity for disabled candidates?

The attitude to people with disabilities is the same as to other applicants. They are the most sensitive at job interviews. The problem is that people with disabilities are afraid to send their CVs, for they lack self-confidence. The Labour Law does not demand such requirements. They are regulated only by 


\section{SHS Web of Conferences}

the employer according to his honorary mind and morality principles. The State Employment Agency (NVA) offered to employ PwD in the frame of the special 2 year state project, which is financed by the Latvian State, and therefore is beneficial for the company. Persons with disabilities are recruited by the specialists of NVA Specific procedures do exist only in specific State projects, NVA does the recruitment process.

Q2. Are there alternative ways of testing the skills required for the job rather than relying on standard paper qualifications which some disabled people may have been denied the opportunity to obtain?

There are no alternative ways of skills testing for people with disabilities. These ways depend on certain employer/personnel department manager understanding and on the requirements of a concrete position for a certain applicant. The alternative ways of skills' testing are not developed in Latvia. At this enterprise in each specific case a separate commission assesses an applicant - a disabled person's compatibility with the vacant position. It should be mentioned that some people are awarded higher qualifications than they really possess.

Q3. Are health requirements justifiable for workplaces?

Health requirements are justifiable for workplaces partly. The biggest problem is the work environment, especially for people with motor disorders, for example, a watchmaker in a wheelchair with the first group of disability works at the enterprise. To improve working conditions for this person the employer has rearranged the $1^{\text {st }}$ floor working space. Another example, the enterprise has received special financing (Fund for Afghan Disabled Workers) which ensures the creation of necessary work places and working space reconstruction in accordance with the standards. Working places and working space are specially equipped.

Q4. Are the recruitment staff and selection panel members trained in equal opportunities, diversity issues and disability awareness?

There is no formal training of this kind in Latvia. Personnel recruitment specialists acquire the necessary knowledge mainly by receiving consultation from the specialists of the State Employment agency and other institutions, which award qualifications to people with disabilities. The preparation of such specialists is not performed at any educational institution at any level. The standards of the preparation of such specialists are not worked out also.

Q5. Is there disabled employee as member of recruitment panels?

A disabled employee is not usually members of recruitment panels, because there are no people with the same group of disability at this small enterprise. Specialists of this kind do not work at the enterprise and there is no possibility to invite them. A person with disability participates in a job interview as an expert sometimes.

Q6. Are applicants with disabilities invited to identify any particular arrangements they might need at the interview?

The arrangements of this kind are not officially formulated. The managers of the enterprise try to get acquainted with the materials on positive foreign experience before the job interview with a person with disability. It would be necessary, but official directions of this kind were not received.

Q7. Is the same scoring/assessment system used for disabled and non-disabled candidates?

Yes. Different scoring/assessment system is applied. Different evaluation systems are applied depending on the particularities of a certain position.

Q8. Is a disabled person consulted where modification or refurbishment work is planned, to the workstation or premises, prior to commencing the work? Are individuals asked if the modifications meet their needs?

There are general regulations on construction, which require the corresponding needs of disabled people. If people with disabilities work at this enterprise such consultations take place. Special survey was not performed because there are general regulations on construction in Latvia, which are to be followed. Small changes in the working place equipment are done almost always when people with certain disabilities are hired.

Q9. Is it ensured that information about any practical consequences of an individual's disability is only passed on to the rest of the staff and managers necessary with the person's consent? 


\section{Int. Conf. SOCIETY. HEALTH. WELFARE; Congr. of Rehabilitation Doctors of Latvia}

Individually, only with the agreement of a disabled person, if a person is willing to do it.

Q10. Are managers and colleagues aware of any additional support and guidance that will help a new recruit to do his/her best in the job? Is it ensured that accommodation staff is aware of the arrangements required by newly recruited disabled staff (workstation, toilets, canteens, rest rooms, emergency and evacuation procedures, etc.) and that those requirements are met in advance of the candidate's starting date?

Managers and colleagues understand the situation and support people with disabilities. The demands regarding equipment at a working place are met. Sometimes working place changes are performed after a person is hired. Offices are equipped in accordance with the needs of the employment of people with movement disabilities: desks are specially adjusted for the work at the computer, there are no doorsteps between the rooms, toilets and kitchens are fitted for wheelchair users, etc.

Q11. Are managers, colleagues, trade union officials, and first aid staff aware of the practical consequences of an individual's disability?

Yes, for in the other way normal employment of this person is not possible. Or the agreement to solve this problem is concluded. For example, at this enterprise a watchmaker has to go to his apartment to use the toilet. The needs of people with asthma and epilepsy are satisfied only partly.

Q12. Is there a clearly defined job description and explanation of duties available at the earliest opportunity and does it form part of the induction process?

The induction process starts with the explanation of duties and expectations from the side of the company. Job descriptions are clearly defined. The direct managers explain every day duties before a concrete task is given. It depends on the position of people with disability in the company and their disability group. Disabled persons with mental diseases - company has 2 persons- are carefully observed by a psychologist.

Q13. Is a disabled person consulted where modification or refurbishment work is planned, to the workstation or premises, prior to commencing the work? Are individuals asked if the modifications meet their needs?

Yes, obligatory. It is examined regularly by the State Labour Inspectorate. Getting acquainted with these documents is the part of hiring process.

Q14. Are there monitoring checks implemented to see whether people with disabilities are overrepresented in rejection decisions for positions. If any patterns emerge, is the whole recruitment process checked?

No, the Monitoring Boards of this kind do not exist in Latvia.

Summarizing the answers of the respondents from the employers' side on developing disability management in the workplace the following is revealed: at first, there is established a substantial change from a negative model "Why should I hire the disabled person if I can hire normal unemployed person" (Živitere, 2008) to social inclusion model, nevertheless, employers don't consider the management of disability issues in the workplace, as the ILO recommend, a priority task which contributes to business success, and regard it as an integral part of the workplace human resources development strategy (International Labour Office, 2002); the second, the predominant not just special employment services for people with disabilities, but also employment-enhancing measures in all policy areas - "mainstreaming model" reduce rather than increase employment opportunities for people with disabilities; the third, success, problems and difficulties in economic, legal and social sectors, as well as the opportunities and identify the areas of improvement in further.

\section{Results}

The results of the study are based on the authors' survey and study the analytical review of the secondary resources about the current situation on management of the disabled and interviewing of employers in order to clarify problems. 


\section{SHS Web of Conferences}

Management of the disabled has been developed. Corporative aims of the enterprise are set as socially responsible ones, which determine the corporate culture and following the principle of equality of human rights of all employees. All the employees try to be open to others. Top managers and administration pay great attention to this. Discussions are organized on the distribution of duties depending on special abilities of a newly employed person taking into account his disability as well as training and the improvement of qualifications.

Respondents: the employers feeling is that state institutions do not consider people with disabilities as a prospective labor force. None of the state agencies mention people with disabilities as possible employees in their medium-terms planning documents or developmental strategy, they do not include special training programmes, internship programmes or other issues dealing with employment of people with disability. Moreover, the quality of answers provided shows incompetence of employees of state institutions regarding disability aspects and confirm dogmas existing in society - people with disabilities cannot and should not work.

\section{Discussion}

- The employers and staff of the enterprises are not prepared to engage people with disabilities. There is a demand for professionally trained specialists. Formal preparation of HRM for hiring of people with disabilities is a necessity.

- The support of the state is important, but it does not ensure all the necessary additional payments to wages, which arise in connection with the lower efficiency of the work of people with disabilities and ability to do the work qualitatively sometimes. These expenses are covered by the enterprise.

- Partial rebate of social tax could be very efficient, for example, a special employers' stimulation system is desirable: tax allowances, providing additional payments to specialists which perform special training at working places. Develop financial support programs for employers for covering costs of reasonable accommodation of working places for people with disabilities.

- The legal foundations and state policies of the employment of people with disabilities are not sufficient.

- The existing environment of entrepreneurship, main obstacles doesn't facilities the employment of disabled people or the interests of entrepreneurs in firing disabled people and developing a disability management in the workplace in Latvia.

\section{Conclusions}

Developing a disability management in the workplace, as this research shows, has been evaluated in keeping with the European Disability Strategy 2010-2020 objectives and fighting against social exclusion and practical implementation of United Convention on the rights of this group of persons. For this reason, a level playing field of a contribution from the state side and updating of the employers' and managers' knowledge and competencies would be evaluated.

This research has been made by Information Systems Management Institute with the financial support of the Education and Culture Lifelong Learning Programme Leonardo da Vinci. The authors of this paper are indebted to the hard work of the Project "Ability not Disability in the Workplace" research team. We would like to thank Tino Boubaris, Anke Egblomasse, Rita Bencivenga, Allesandra Tinti, Dziuginta Valeckiene for their strong support as Project Partners and Gunta Ancha for her very helpful comments on the research and our special gratitude to Roman Dyakon for his administrative support. We are particularly indebted to the participants in our research; without their enthusiasm and readiness to share their experiences, this study would not have been possible. We are also thankful to our interview transcribers for the quality of their work, their consistency and diligence. 
Int. Conf. SOCIETY. HEALTH. WELFARE; Congr. of Rehabilitation Doctors of Latvia

\section{References}

[1] ANED Facts and figures (2010) Report on the employment of disabled people in European countries-Latvia. http://www.disability-europe.net/en/countries/ Latvia?jsEnabled=1

[2] Bučiūniené, I., Kazlauskaité, R. (2010) Integrating people with disability into the workforce: the case of a retail chain. Equality, Diversity and Inclusion: An International Journal, 29 (5), p. 53438. www . emeraldinsight. com/2040-7149.htm.

[3] Coskun, R., Živitere, M., Alexandrova, S., Firat, S. (eds.). (2009) Disabled People and Employability (Leonardo da Vinci project Increasing Employability of Disabled People). Sakarya: Sakarya University.

[4] Employment Agency Marketing Survey (2011) State Employment Agency of Latvia. Services for persons with disabilities. http://www.docstoc.com/docs/70397149/

[5] European Commission (2011) European Disability Strategy 2010-2020: A Renewed Commitment to a Barrier-Free Europe. http: //eur-lex . europa.eu .

[6] Ilena, I. (2007) Employment opportunities for the people with disabilities. $I^{\text {st }}$ International and Interdisciplinary Conference "FIHUSO-2007” merging Physical Sciences, the Humanities and Social Sciences, 18-19 May, 2007. Kaunas.

[7] International Labour Office (2002) Managing disability in the workplace. Geneva: ILO code of practice.

[8] International Labour Office (2010) Disability in the workplace: Company Practices. Geneva.

[9] IZA. Research Report 29. (2010) Mobility and Integration of People with Disabilities into the Labor Market (2010). IP/A/EMPL/FWC/2008-002/C1/SC4.

[10] Lifelong Learning Programme Leonardo da Vinci project Ability not Disability in Employment (2009-2011). 2009-1-LV1-LEO05-00370.

[11] Persons with disability in Latvia (2006). [Personas ar invaliditāti Latvijā, 2006]. Svarīgākie sociālekonomiskie, demogrāfiskie un nozares rādītāji. Statistikas biļetens. 2002 - 2006. Rīga.

[12] Roulstone, A., Gradwell, L., Price, J., Child, L. (2003) How disabled people manage in the workplace. Thriving and surviving at work. Disabled people's employment strategies. http: //www.jrf .org.uk/publications

[13] Shrey, D.E. Disability management at the workplace: overwiev and future trends: Portions of this article have been adapted from Shrey and Lacerte (1995) and Shrey (1995). http: //www. ilo. org/safework_bookshelf/english? content\&nd=857170197

[14] Treasury Board of Canada Secretariat. OCHRO Human resources management. http://www.tbs-sct.gc.ca/hrh/wds-mst/disability-incapacite04-eng.asp

[15] Živitere, M. (2007) The employment of people with disabilities. $1^{\text {st }}$ International and Interdisciplinary Conference "FIHUSO-2007" merging Physical Sciences, the Humanities and Social Sciences, 18-19 May, 2007. Kaunas.

[16] Waldschmidt, A. (2009) Disability Policy of the European Union: The Supranational Level, ALTER. European Journal of Disability Research / Revue Européenne de Recherche sur le Handicap, 3, (1), 2009. 